\title{
Adaptation planning in Caribbean Small Island Developing States: A literature review
}

\author{
Adelle Thomas
}

Planned adaptation has been recognised as essential to address the implications of climate change for Small Island Developing States (SIDS). Many SIDS have developed national, sub-national, and sectoral adaptation plans. The Caribbean Climate Risk and Adaptation Tool (CCORAL) has been developed and utilised broadly throughout the region to guide practitioners in adaptation planning. This chapter utilises the CCORAL framework of adaptation planning to develop the concept of an adaptation planning cycle. It uses this conceptualisation as a framework to assess academic literature focused on Caribbean SIDS that aligns with different aspects of the adaptation planning cycle. Through this exercise, the strengths and gaps in existing peer-reviewed literature are identified in order to inform future research needed to assist in adaptation planning for the region.

Cite this article: Thomas, A. (2019): Adaptation planning in Caribbean Small Island Developing States: A literature review. In: Klöck, C. \& Fink, M. (eds.): Dealing with climate change on small islands: Towards effective and sustainable adaptation? (pp. 123-140). Göttingen: Göttingen University Press. https://doi.org/10.17875/gup2019-1214 


\section{Introduction}

Small Island Developing States (SIDS) across the globe are well recognised for their high vulnerability to impacts of climate change (UN-OHRLLS, 2017). While these small islands have negligible contributions to the global greenhouse gas emissions that drive climate change, they are highly exposed to climatic hazards (Nurse et al., 2014). Thus, while both mitigation and adaptation are essential to reduce impacts of climate change, many SIDS have concentrated their climate action on adaptation (Mycoo, 2017; Robinson, 2017). This is certainly the case in the Caribbean, where adaptation planning and implementation has begun in earnest.

The Caribbean Community Climate Change Centre (CCCCC) was developed as the body responsible for supporting the region in addressing climate change and developing programs to facilitate sustainable development in the context of climate change (Thomas \& Lindo, 2019). Since becoming fully operational in 2004, the CCCCC has implemented a variety of projects and programs that support climate resilient development in the region. To guide action in the Caribbean, the CCCCC developed the Regional Framework for Achieving Development Resilient to Climate Change in 2009 and advised countries to take a risk management approach in considering the challenges of climate change in their development plans (CCCCC, 2009). To support science-based decision-making, the CCCCC developed regionally specific climate change risk management and adaptation planning guidance. One of the guidance tools developed in 2012 is the Caribbean Climate Risk and Adaptation Tool (CCORAL). CCORAL facilitates assessing climate change impacts in projects, programs, strategies, or legislation and is intended to mainstream climate change adaptation across planning in the region. The tool takes users through a multi-step process intended to understand the climate influence on potential activities and identify prospective adaptation actions that can be implemented to reduce risk. Training with CCORAL has been conducted in all of the member states of the Caribbean Community (CARICOM) with over 500 individuals in government, non-governmental organisations, banks, and regional organisations (Thomas \& Lindo, 2019).

As adaptation planning has increased in the region, academic research on adaptation in Caribbean SIDS has also been growing. The majority of publications focus on governance, institutions, and planning (Robinson, 2018). This chapter utilises the CCORAL framework of adaptation planning to develop the concept of an adaptation planning cycle. It then uses this conceptualisation to assess academic literature focused on Caribbean SIDS that aligns with different aspects of the cycle. Through this exercise, it identifies the strengths and gaps in existing peer-reviewed literature that can inform future research needed to assist adaptation planning for the region. 


\section{$2 \quad$ Conceptual Framework}

Literature reviews of adaptation have taken a variety of forms, from assessing literature on adaptation responses for specific geographic locations (Hunt \& Watkiss, 2011), to reviewing publications on distinct approaches to adaptation, such as community-based adaptation (Forsyth, 2013). Literature reviews on adaptation planning in particular have also varied in their approaches. For example, Araos et al. (2016) use a systematic review framework to identify adaptation planning in large cities while Walker, Haasnoot, and Kwakkel (2013) review planning approaches for adaptation that take uncertainty into account. This chapter takes a novel approach to reviewing literature on adaptation by assessing peer-reviewed studies that align with adaptation planning guidance that has been developed for practitioners in the Caribbean. Since CCORAL has been used extensively in the region to plan adaptation, an assessment of how the academic literature fits within the CCORAL framework provides a practitioner-focused assessment of scientific research.

CCORAL provides a framework and resources to allow users to identify appropriate adaptation actions. Resources that CCORAL recommends include several 'end-to-end' climate risk management tools that contain guidance on moving from assessing vulnerability to determining risk to identifying, appraising, and costing adaptation options. These tools were recommended for their relevance to the Caribbean context and to Caribbean decision-making processes (CCCCC \& Acclimatise, 2015). The first of these risk management tools is the Caribbean Risk Management Guidelines for Climate Change Adaptation Decision Making which provides a risk management framework to identify and implement adaptation options focused specifically on the Caribbean (CARICOM Secretariat, 2003). The second tool is the Climate, Environment and Disaster Risk Reduction Integration Guidance, which provides guidance for countries to integrate adaptation, disaster risk reduction, and environment into development (CEDRIG, n.d.). Last, Climate Proofing for Development is a guideline to incorporate climate change into development planning and offers a methodology for identifying and prioritising adaptation options (Hahn \& Fröde, 2011).

All of these guidelines include assessment of risk and vulnerability as well as clear steps for identifying, assessing, selecting, and costing adaptation options. These are common features of guidelines for adaptation planning in many frameworks beyond those identified by CCORAL. For example, the United Kingdom Climate Impacts Programme (UKCIP) has proposed a step-by-step methodology to move from identifying problems through to monitoring action (UKCIP, 2010). There are also a host of other frameworks and guidelines that follow a similar approach (e.g. US National Climate Assessment Framework, WeAdapt Adaptation Planning).

From the guidelines and frameworks recommended by CCORAL, the process of adaptation planning can be generalised as including the following steps: 
(i) assessment of impacts, vulnerability, or risk;

(ii) identification of adaptation needs and options;

(iii) prioritisation of adaptation options;

(iv) selection and elaboration of adaptation strategy;

(v) implementation of adaptation strategy; and

(vi) monitoring and evaluation of adaptation strategy.

The process is intended to be cyclical with monitoring and evaluation then feeding back into assessing how impacts, vulnerability, or risk have been affected due to implementation of the adaptation strategy (CARICOM Secretariat, 2003). The planning process may also be iterative and several steps may be repeated (CEDRIG, n.d.; Hahn \& Fröde, 2011). For example, identification and prioritisation of adaptation options may go through several cycles before moving to the next step of selecting and elaborating on a particular adaptation strategy. The process of elaborating on the adaptation strategy may reveal weaknesses or gaps in the strategy selected and require conducting the identification and prioritisation stages again. Thus, the adaptation planning process is flexible but, ideally, all steps should be taken in order for effective adaptation to take place.

While this framework encapsulates the practical steps that should be taken to plan adaptation, it is missing discussion of the contextual environment that planning takes place in. Wise et al. (2014) highlight that adaptation planning takes place in an "adaptive space" where a number of factors - such as cultural, political, economic, and environmental characteristics of a particular place - affect the procedural aspects of adaptation planning. There are a number of challenges and barriers in the adaptive space that can affect the outcomes of adaptation planning. These include coordination challenges between different areas of government, issues of engagement with a variety of sectors, the need for effective leadership of the planning process, availability of funding, and integration of adaptation into non-climate focused policies and plans (Mimura et al., 2014). Thus, the process of adaptation planning is very much influenced by the context in which the planning takes place.

Figure 1 presents the adaptation planning process and adaptive space, highlighting the iterative process between planning steps and that these steps take place in a particular contextual environment. The combined procedural processes and contextual environment is termed the adaptation planning cycle for the purposes of this chapter.

Using this conceptualisation of the adaptation planning cycle, I conducted an extensive literature search to identify peer-reviewed literature that addressed any of the components of the cycle and that included Caribbean SIDS in particular. I assessed literature that included at least one Caribbean SIDS including crossregional SIDS studies and studies that did not focus on SIDS in particular. I reviewed literature to determine which aspect of the adaptation planning cycle it focused on and evaluated the major findings from each paper. 


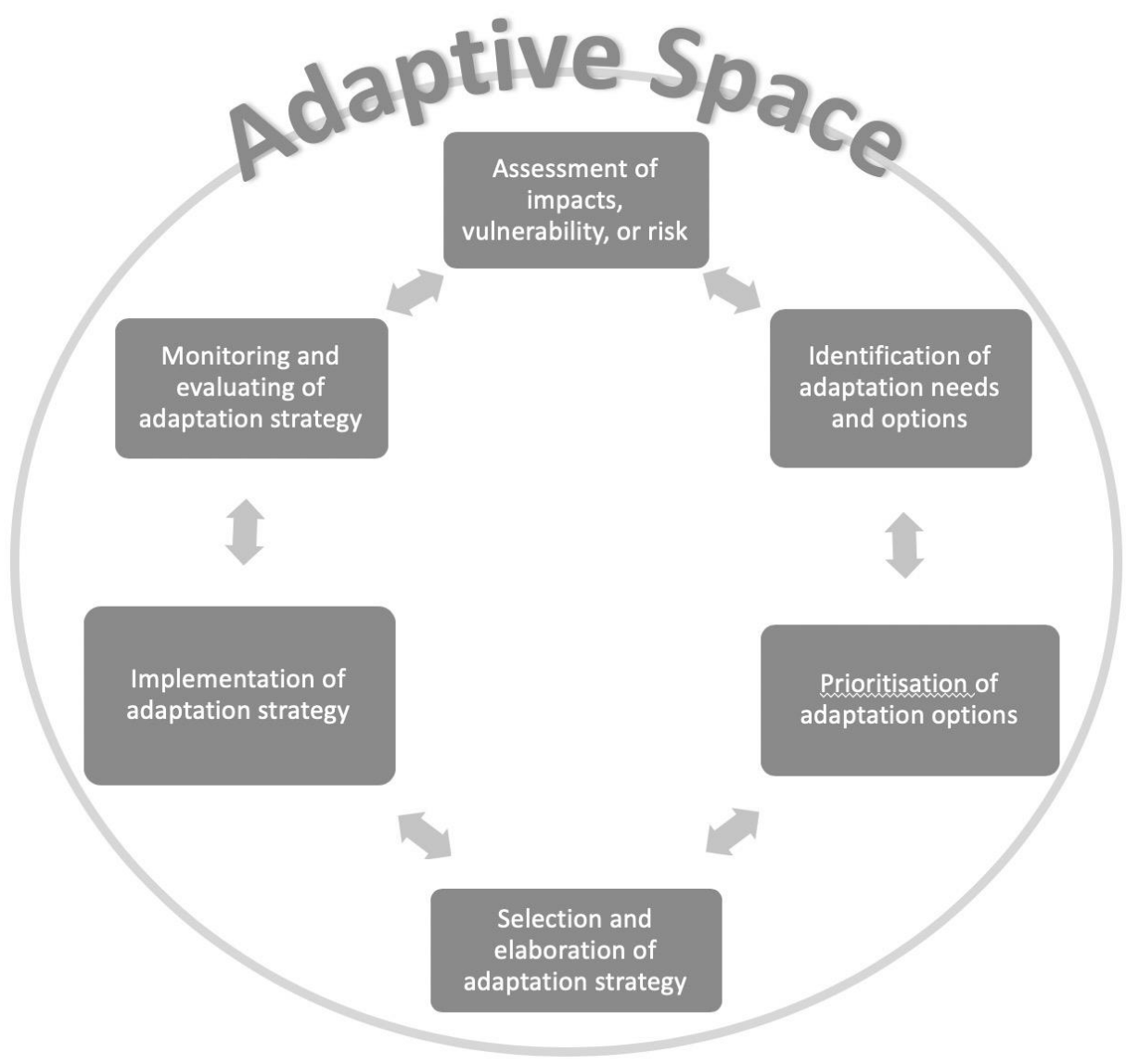

Figure 1: Adaptation Planning Cycle

I found additional studies that address climate change and Caribbean SIDS during the literature search that did not focus on the stages of the adaptation planning cycle. While these studies are valuable and add to the broader literature available on Caribbean SIDS, this particular literature review assesses only studies that focus on topics that are part of the adaptation planning cycle. Thus, this chapter is not an exhaustive review of all peer-reviewed literature on climate change and Caribbean SIDS.

Each of the papers relevant for this literature review are further detailed in the following sections: 3.1 Adaptive space, 3.2 Assessment of impacts, vulnerability or risk, 3.3 Identification and prioritisation of adaptation options, 3.4 Implementation of adaptation strategy, and 3.5 Monitoring and evaluation of adaptation strategy. I combined literature on identification and prioritisation of adaptation options into one section since the found literature addressed both of these issues, despite the 
separation of these steps in the adaptation planning cycle. I did not find any studies that focused on selection and elaboration of the adaptation strategy.

\section{$3 \quad$ Literature review}

\subsection{Adaptive space}

Robinson (2018) uses a resilience lens to identify limits to adaptation at the national level in Caribbean SIDS. Analysing National Communications (NCs) submitted to the United Nations Framework Convention on Climate Change (UNFCCC) and interviews with governmental officials, the study identifies limits to adaptation that are related to the adaptive space. These limits include lack of finances, limited technical capacity and resources, lack of data and records, and issues related to human resources. Financing and organisational capacity are identified as the major limits to adaption planning and implementation and include lack of national funding, limited skilled labour, and ineffective governance structures.

Robinson and Gilfillan (2017) assess the effectiveness of regional climate change adaptation organisations in both the Caribbean and Pacific, focusing on the CCCCC in the Caribbean. Regional organisations have the potential to provide financial, technical, and capacity-building support for SIDS governments in the adaptation planning cycle. However, there have been very few assessments of their effectiveness in coordinating regional adaptation strategies and programs. The authors develop a qualitative tool - Framework for Assessing Regional Organizations Coordinating Climate Change Action (FAROCCCA) - and use it, along with interviews of regional experts, to assess the CCCCC. Strengths of the organisation include an institutional framework that supports adaptation, high-capacity staff, access to financing streams, polices/plans that support climate research, and achieving immediate outputs of adaptation projects. Weaknesses include challenges in retaining staff, limitations in evidence-based project design, and questionable effectiveness of projects at sub-national scales. The authors identify potential areas of improvement which include developing robust indicators for monitoring and evaluation of adaptation projects, and strengthening the design of projects and programs. To be most effective at supporting adaptation, the authors suggest that instead of focusing on project implementation, regional organisations should focus on filling information deficits, assisting countries to develop financeable projects and access funding, and building national capacity.

Robinson (2017) explores drivers and barriers of mainstreaming adaptation into policies and programs at the national level in Caribbean and Pacific SIDS. Drawing from interviews with national governmental representatives and regional organisations, the study identifies a number of drivers of adaptation mainstreaming. These include the effectiveness of institutions or organisations, the presence of a climate 'champion' that can utilise connections with informal networks, and high 
levels of risk and exposure. Barriers to mainstreaming are found to include weak planning and governance, limited human resources, and lack of coordination of development priorities.

Betzold (2015) reviews literature on adaptation in small islands across regions. The article focuses on barriers to adaptation that are categorised as relating to perception and awareness, resources, and institutions. Religious beliefs, along with the view of climate change as a foreign concept by SIDS residents, relate to the low prioritisation of adaptation action. Reliance on foreign aid may lead to adaptation efforts being focused on those prioritised by donors while also discouraging the usage of limited domestic funds on adaptation. The need for extensive local participation and ownership in adaptation is identified as a fundamental requirement for successful adaptation. While Betzold utilises literature from across SIDS regions, including the Caribbean, much of the literature she surveys focuses on Oceania and the author calls for further research on these topics from different regions to facilitate cross-regional comparison.

Tompkins, Lemos, and Boyd (2008) conduct an ethnographic study of disaster risk reduction approaches in Cayman Islands and Brazil and make linkages to effects on adaptive capacity to climate change. In the Cayman Islands, they identify factors that contributed to the decreased vulnerability of the territory to hurricanes, and the reduced impact of these storms, as compared to other islands in the region. The factors are all related to the capacity and efficiency of the national institution tasked with hurricane management and include support and buy-in from both key stakeholders and the wider population, annual revisions of plans and strategies based on the experiences of each hurricane season, and a focus on mainstreaming disaster risk reduction into all areas of policymaking.

Tompkins (2005) also focuses on the Cayman Islands to explore factors that contributed to improved national responses to weather risks and climate change adaptation planning. The study assesses changes to government institutions in response to multiple hurricanes focusing on constitutional order, rules, regulations, and organisational arrangement. The study finds that the institution or agency responsible for adaptation planning should operate as a learning-based organisation that is flexible and able to change with the development of new information. Adaptation planning agencies should be integrated across government departments and ministries and include a wide array of stakeholders. Such agencies should also remain abreast of up-to-date information and use this knowledge to advance guidance and advice. Tompkins also identifies a number of actions that can be undertaken to increase the profile of climate change and contribute to planned adaptation at the national scale. These include: (i) compiling clear information on climate change hazards and impacts, (ii) integrating this information into physical planning processes, (iii) providing education and awareness raising for all parts of society, and (iv) mainstreaming the usage of climate risk assessments across all areas of government planning and policymaking. 
This review of literature focused on the adaptive space shows a number of factors that affect the contextual environment in which adaptation planning takes place. The most commonly discussed factor is institutional capacity. All of the literature reviewed highlights that the institution or organisation responsible for adaptation plays a critical role in the planning and implementation of adaptation. It appears that institutional capacity plays an even larger role in the adaptive space than availability of or access to funding, which is also identified as a significant factor. As detailed by Robinson (2018), the capacity of institutions affects how SIDS are able to access international funding that may reduce reliance on limited national funds.

Perception and awareness of climate change is also identified as a key factor in the adaptive space that affects awareness of risk and exposure and public support for adaptation (Betzold, 2015; Robinson, 2017; Tompkins et al., 2008). The availability of information, data, and records on climate change also affects the process of adaptation planning since without needed material, it is difficult to identify the need for adaptation or to develop effective strategies (Robinson, 2018, Tompkins et al., 2008; Tompkins, 2005). Regional organisations such as the CCCCC were identified as being able to improve the adaptive space at the national level through addressing challenges such as information deficits, which would alleviate the lack of data and records; providing assistance with developing financeable projects, which would address limited technical capacity, human resources constraints, and lack of funding; and providing national capacity building, which would improve institutional capacity (Robinson \& Gilfillan, 2017).

\subsection{Assessment of vulnerability, impacts, and risk}

My research did not find any studies focused on the process or analysis of vulnerability, impact, or risk assessments as part of an overall adaptation planning process. However, there are a plethora of studies that evaluate vulnerability, risk, and impacts of climate change for Caribbean SIDS. For example, Donner, Knutson, and Oppenheimer (2007) use global climate models to evaluate the effect of climate change on the 2005 Caribbean coral bleaching event that resulted in damages to coral reefs across the region. They find that as global temperatures rise the likelihood of continued mass bleaching will increase. Scott, Simpson, and Sim (2012) evaluate the vulnerability of tourism properties and economic activities in the coastal zone to rising sea levels across CARICOM. They find that with $1 \mathrm{~m}$ of sea level rise, $60 \%$ of resort properties would be at risk of beach erosion damage and approximately $30 \%$ of resort properties would be either partially or fully inundated. Lewsey, Cid, and Kruse (2004) assess projected impacts of climate change on coastal infrastructure in the eastern Caribbean, identifying factors that may lead to increased impacts including location of critical infrastructure in high-risk areas and degradation of coastal ecosystems. Cambers (2009) utilises beach monitoring data to highlight beach erosion trends across eight Caribbean islands showcasing in- 
creased erosion in islands that have been affected by tropical cyclones. Cashman, Nurse, and John (2010) use climate modeling to project changes in temperature and rainfall across the Caribbean and resultant implications for water resource availability.

The above studies are illustrative of the literature that focus on evaluation of vulnerability, risk, and impacts of climate change for Caribbean SIDS. There are a range of studies that assess climate change risks, impacts, and vulnerabilities across different sectors, such as transportation (Monioudi et al., 2018), tourism (Scott, Simpson, \& Sim, 2012), agriculture (Lallo et al., 2018; Popke, Curtis, \& Gamble, 2016; Rhiney, Eitzinger, Farrell, \& Prager, 2018), freshwater (Donk, Van Uyvten, Willems, \& Taylor, 2018; Karnauskas, Schleussner, Donnelly, \& Anchukaitis, 2018), and fisheries and marine-dependent livelihoods (Baptiste \& Kinlocke, 2016; Forster, Lake, Watkinson, \& Gill, 2014). Other studies examine impacts for marginalised societal groups (Baptiste \& Rhiney, 2016; Dulal et al., 2009; Hogarth \& Wójcik, 2016; Kelman, 2010; Middelbeek, Kolle, \& Verrest 2014; Smith \& Rhiney, 2016), for the region as a whole (Rhiney, 2015), or for the climate and ocean (Karmalkar et al., 2013; Palanisamy, Becker, Meyssignac, Henry, \& Cazenave, 2012). This review underscores that there are many studies that fall under this category of the adaptation planning cycle without being exhaustive in detailed assessment of all such studies.

The many studies that provide assessments of risk, vulnerability, and impacts highlight that this is the part of the adaptation planning cycle with the highest amount of research. While I found no studies that evaluate the process of conducting vulnerability, risk, or impact assessments as part of the adaptation planning cycle, the studies that do exist provide valuable input for practitioners tasked with conducting such assessments to inform adaptation strategies.

\subsection{Identification and prioritisation of adaptation options}

Feld and Galiani (2015) provide a range of adaptation options that may be effective in Latin America and the Caribbean. Adaptation practices and policies are provided by sector for water resources, coastal zones, agriculture, livestock, energy, biodiversity, and health. A review of cost-benefit analysis as a methodology to select context-specific adaptation measures from a range of options is provided along with discussion of the limits of this approach. While the paper claims to be applicable to the Caribbean, the vast majority of literature cited and discussed centres on Latin America with no discussion of the particularities of small island contexts.

Mercer et al. (2012) review ecosystem-based adaptation (EBA) in Caribbean SIDS, with a particular focus on assessing the usage of local knowledge in developing adaptation strategies and integration of local knowledge with external knowledge. While regional and national adaptation actions have stressed the importance of ecosystems, there is a focus on coastal ecosystems and very limited 
inclusion of the relevance or benefits of including local knowledge in developing adaptation measures. However, at the local scale, non-governmental organisations are the key actors in developing and implementing EBA approaches and at this scale there is much attention given to integrating local and external knowledge. Nevertheless, methodologies or approaches for effectively integrating different types of knowledge are seldom provided in the limited project documentation that is included. The authors detail the strengths and weaknesses of a variety of methodologies that can be used to integrate local and external knowledge for adaptation and highlight the need for EBA approaches to be applied to the array of ecosystems at risk in the region rather than continuing to focus on coastal ecosystems. Actions to improve the usage of EBA and integrate local and external knowledge are provided including the need for local champions, drawing upon previous development experience, and regular monitoring and evaluation of climate change adaptation in general.

These were the only two studies found that detail adaptation options available for SIDS. While Feld and Galiani (2015) provide a range of adaptation options across various sectors, the study lacks consideration of the specific context of SIDS. Including consideration of SIDS-specific characteristics, such as limited economies of scale and small land area, is essential in research on adaptation options that are applicable for Caribbean SIDS. Mercer et al. (2012) do focus on SIDS and underscore the importance of including local knowledge when identifying and evaluating adaptation options.

\subsection{Implementation of adaptation strategies}

Mycoo (2018) reviews current adaptation strategies in the Caribbean and assesses their feasibility if global average temperatures were to exceed $1.5^{\circ} \mathrm{C}$ above preindustrial levels. Adaptation strategies that have been implemented by Caribbean SIDS in the past or that may be required for future climate impacts are assessed for their feasibility as global temperatures warm. Adaptation strategies are categorised according to human settlements and coastal infrastructure, integrated coastal zone management and coastal setbacks, health, EBA, economic diversification, freshwater resources and water security, and disaster risk reduction. The study finds that while Caribbean SIDS have been innovative in adapting to climate change thus far, there is a need for substantial scaling up and acceleration of implementation as temperatures increase. Given the significant challenges that further climate impacts pose to SIDS and limited human, technical and financial capacities at the national scale, it is essential that prioritisation of adaptation options takes place.

Robinson (2018) identifies trends in adaptation action in Caribbean SIDS using analysis of National Communications submitted to the UNFCCC. The most commonly reported adaptation action was assessment of vulnerability and impacts, followed by adaptation research and workshops or trainings. Interviews with gov- 
ernment officials in the region revealed that most adaptation strategies include public education and awareness, development of climate change policies, and organisational capacity building. The majority of adaptation strategies were identified as taking place in the water, agriculture, and coastal resources sectors with some limited action in forestry, fisheries, and tourism.

Ebi, Lewis, and Corvalan (2006) review strategies, policies, and measures that small islands across regions have taken to adapt to increased vulnerability to climate-sensitive diseases. In the Caribbean, health organisations recommend a variety of adaptation measures including improving public health infrastructure, creating enabling environments, improving water systems, and strengthening vaccination programs. Drawing from research conducted across SIDS regions, the authors identify recommendations to improve adaptive capacity in the health sector. These include (i) increasing research on climate-sensitive diseases, (ii) building institutional capacity, (iii) improving awareness of health implications of climate change, and (iv) implementing long-term adaptation strategies, policies, and measures.

Literature that assesses the implementation of adaptation strategies in Caribbean SIDS shows that adaptation has taken place across sectors and at a variety of spatial scales. Adaptation strategies often include public education and capacity building. However, as highlighted by Mycoo (2018), as climate risks increase there is a need for substantial scaling up of adaptation across the region. Small, incremental adaptation strategies may be insufficient to address increased risks. In the light of limited funding and institutional capacity, Caribbean SIDS must prioritise and escalate adaptation strategies.

\subsection{Monitoring and evaluation of adaptation strategies}

Despite the importance of monitoring and evaluation being mentioned in several of the papers that were reviewed (Mercer et al., 2012; Mycoo, 2017; Robinson, 2018), there is a paucity of peer-reviewed studies that focus on this stage of the adaptation planning cycle. Scobie (2018) assesses accountability in climate change governance in the Caribbean, drawing from a survey and interviews with Caribbean climate change experts. The study finds that there are limited accountability measures being used in practice due to inadequate resources and perceptions that accountability mechanisms are prohibitive of timely policy implementation.

While there are a number of technical papers and other grey literature on monitoring and evaluation for adaptation in Caribbean SIDS (e.g. Pierre-Nathoniel, 2017; Rahat \& Holvoet, 2016) there is a lack of peer-reviewed literature that addresses specific monitoring and evaluation methodologies and practices that are applicable in the Caribbean context. However, as detailed in studies focused on areas other than Caribbean SIDS, monitoring and evaluation is a critical component of adaptation planning and will be increasingly important as risks escalate (Lamhauge, Lanzi, \& Agrawala, 2013). 


\section{Discussion}

The adaptation planning cycle provides a framework for a practitioner-focused assessment of scientific research. Planning, policies, and actions that are based on science are particularly important when addressing an issue as multi-faceted and complex as climate change (Lacey, Howden, Cvitanovic, \& Colvin, 2018). Additionally, international climate funders increasingly require that project proposals include context-specific science to justify the need for funding and the particular approaches taken to adapt (Carter \& Roux, 2019). Thus, it is imperative that the practice of adaptation planning is supported by scientific research. Assessing academic literature using the adaptation planning cycle therefore allows for identification of strengths and gaps in scientific research that can be used to inform future research needed to support the practice of science-based adaptation planning.

From the literature review, it is clear that some steps in the adaptation planning cycle have received more attention than others. Assessment of vulnerability, impacts, and risk is by far the stage of the adaptation planning cycle with the most research. Studies that focus on this stage provide much-needed assessments of how Caribbean SIDS may be affected by climate change. While no studies were found that evaluate the process of conducting a specific vulnerability, impact, or risk assessment as part of the overall process of adaptation planning, the existing studies provide valuable input for practitioners that must provide scientific evidence of the implications of climate change for specific sectors, communities, or ecosystems.

There were also a number of studies found that focus on the adaptive space and that highlight the importance of the contextual environment in adaptation planning. From these studies, it is clear that institutional capacity, access to funding, perception and awareness, and availability of climate information are critical factors that affect the planning cycle. Regional organisations such as the CCCCC can provide much-needed support to national institutions that must act in the adaptive space to plan adaptation.

Few studies were found that focus on the other stages of the adaptation planning cycle. Research on identification and prioritisation of adaptation options is very limited. This highlights the need for additional studies that include evaluation of SIDS-specific adaptation measures as well as research on methods of prioritisation that take characteristics of SIDS into account. While monitoring and evaluation was identified as an area of critical importance, only one study was found that specifically focuses on this stage of the planning cycle. This underscores the need for studies on specific monitoring and evaluation methodologies and practices that are applicable in the Caribbean context and that can support increased monitoring and evaluation of adaptation strategies in the region.

Research on implementation of adaptation is also scarce. Existing research on this stage shows that while past adaptation measures have largely focused on public education and capacity building, there is a need for substantial scaling up of adap- 
tation in the region and a shift from incremental to transformational adaptation. This is in line with the recent Intergovernmental Panel on Climate Change Special Report on $1.5^{\circ} \mathrm{C}$ which stresses the need for transformational adaptation and mitigation to take place across all sectors (IPCC, 2018). Thus, there is a need for Caribbean-specific studies that focus on opportunities and challenges for transformational adaptation.

Noticeably, there were no studies found that focus on selection and elaboration of adaptation strategies. This may perhaps be due to the highly practical nature of this step which involves using the prior steps of assessing impacts, vulnerability, or risk and then identifying and prioritising adaptation options to select a specific adaptation strategy and elaborate on how the strategy will be implemented. However, while this is a practical step, there is opportunity for scientific research to provide inputs on ideal components of adaptation strategies and issues that should be included in strategies to ensure effective implementation. For example, the elaboration of a "theory of change" is increasingly required by funders to illustrate how particular adaptation strategies selected will achieve adaptation goals (Bours, McGinn, \& Pringle, 2014). Research that is SIDS-specific and focused on particular tools, methodologies, or case studies of how adaptation strategies may be selected and elaborated would be useful.

The imbalance of research on specific stages of the adaptation planning cycle shows where additional scientific study is needed. SIDS are well recognised for their high vulnerability to climate change which is reflective of the many existing studies on vulnerability, impacts, and risks. While there is still a need for further research on vulnerability, impacts, and risks - particularly as climate science improves and global temperatures rise - there is also a need for research to support adaptation planning and action by SIDS. Now that SIDS must upscale adaptation efforts and shift to more transformational approaches to adaptation, scientific research to support the other stages of the adaptation planning cycle is required.

\section{Conclusion}

Assessment of peer-reviewed literature that includes discussion of components of the adaptation planning cycle reveals key insights that are specific to Caribbean SIDS. Much of the available literature focuses on the adaptive space and on assessing impacts, vulnerability, and risk. There is limited literature available on identifying and prioritising adaptation options, on implementing adaptation strategies, or on monitoring and evaluating adaptation. Notably, no studies were found that focus on the selection and elaboration of adaptation strategies.

This review highlights areas where additional research related to the adaptation planning cycle would be beneficial. First, targeted research on ways to improve institutional capacity would address this critical component of the adaptive space. Lack of institutional capacity is repeatedly identified as a barrier to adaptation 
planning and implementation. However, with the exception of Tompkins (2005) there is little consideration of how such capacities can be improved.

Second, literature on adaptation options that are feasible in the Caribbean SIDS context would provide much needed information for identification of appropriate adaption measures. While there has been limited study in this area, there is much room for expansion, particularly in light of increased risk as global temperatures rise. Research that goes beyond incremental adaptation options and considers transformational adaptation strategies that can address heightened impacts due to higher global temperatures would be helpful to assist practitioners in the practice of adaptation planning.

Third, studies on monitoring and evaluating adaptation strategies in the Caribbean SIDS context would be beneficial. As more Caribbean nations implement adaptation, it is critical that such strategies are assessed to determine how they affect vulnerability, risk, and impacts. As detailed in the adaptation planning cycle, each of the components of adaptation planning are related to and inform each other and so failure to include specific components affects the overall process. Monitoring and evaluation are also becoming increasingly important on a global scale, particularly as funders are requesting evidence of the effectiveness of adaptation (Lamhauge et al., 2013).

Last, there is a need for studies on selection and elaboration of adaptation strategies. Scientific research can provide valuable support for practitioners tasked with choosing adaptation measures and providing information on how such measures will be implemented effectively. This step is becoming increasingly important to climate funders and research on ideal components of adaptation strategies and issues that should be included to ensure effective implementation would be highly practical and practitioner-relevant.

As climate risks increase due to rising global temperatures, it is critical that Caribbean SIDS are able to effectively plan and implement adaptation strategies. As revealed by this review of the literature, there are many ways that the adaptation planning cycle in the region can be improved and further study of adaptation will assist in both understanding and strengthening adaptation in Caribbean SIDS.

\section{Bibliography}

Araos, M., Berrang-Ford, L., Ford, J. D., Austin, S. E., Biesbroek, R., \& Lesnikowski, A. (2016). Climate change adaptation planning in large cities: A systematic global assessment. Emironmental Science \& Policy, 66, 375-382.

Baptiste, A. K., \& Kinlocke, R. (2016). We are not all the same!: Comparative climate change vulnerabilities among fishers in Old Harbour Bay, Jamaica. Geoforum, 73, 47-59.

Baptiste, A. K., \& Rhiney, K. (2016). Climate justice and the Caribbean: An introduction. Geoforum, 73, 17-21. 
Betzold, C. (2015). Adapting to climate change in small island developing states. Climatic Change, 133(3), 481-489.

Bours, D., McGinn, C., \& Pringle, P. (2014). The theory of change approach to climate adaptation planning. Phenom Phen: SEA Change CoP and Oxford: UKCIP. Retrieved from https://ukcip.ouce.ox.ac.uk/wp-content/PDFs /MandE-Guidance-Note3.pdf.

Cambers, G. (2009). Caribbean beach changes and climate change adaptation. Aquatic Ecosystem Health \& Management, 12(2), 168-176.

Caribbean Community Climate Change Centre (CCCCC). (2009). CARICOM regional framework for achieving development resilient to climate change (including implementation plan). Belmopan, Belize.

Caribbean Community Climate Change Centre (CCCCC), \& Acclimatise. (2015). CCORAL development report. Belmopan, Belize. Retrieved from http:// ccoral.caribbeanclimate.bz/about.

CARICOM Secretariat. (2003). Caribbean risk management guidelines for climate change adaptation decision making. Adapting to Climate Change in the Caribbean (ACCC) project. Georgetown, Guyana.

Carter, S., and Roux, J. (2019). Feature: Understanding climate impacts builds rationale for adaptation finance. CDKN. Retrieved from https://cdkn.org/2019/04/ feature-understanding-climate-impacts-buildsrationale-for-adaptation-finance/?loclang=en_gb.

Cashman, A., Nurse, L., \& John, C. (2010). Climate change in the Caribbean: The water management implications. The Journal of Environment \& Development, 19(1), 42-67.

CEDRIG. (n.d.). Climate, Environment and Disaster Risk Reduction Integration Guidance (CEDRIG) operational: Detailed assessment and integration. Switzerland. Retrieved from https://www.cedrig.org/sites/default/themes/cedrig/img/CEDRIG_ Operational_EN.pdf.

Donk, P., Van Uytven, E., Willems, P., \& Taylor, M. A. (2018). Assessment of the potential implications of a $1.5^{\circ} \mathrm{C}$ versus higher global temperature rise for the Afobaka hydropower scheme in Suriname. Regional Environmental Change, 18(8), 2283-2295.

Donner, S. D., Knutson, T. R., \& Oppenheimer, M. (2007). Model-based assessment of the role of human-induced climate change in the 2005 Caribbean coral bleaching event. PNAS, 104(13), 5483-5488. Retrieved from http://coralreefwatch.noaa.gov/caribbean2005.

Dulal, H., Shah, K., Ahmad, N., Dulal, H. B., Shah, K. U., \& Ahmad, N. (2009). Social equity considerations in the implementation of Caribbean climate change adaptation policies. Sustainability, 1(3), 363-383.

Ebi, K. L., Lewis, N. D., \& Corvalan, C. (2006). Climate variability and change and their potential health effects in small island states: Information for adaptation planning in the health sector. Environmental Health Perspectives, 114(12), 1957-1963. 
Feld, B., \& Galiani, S. (2015). Climate change in Latin America and the Caribbean: Policy options and research priorities. Latin American Economic Review, 24(1), 14.

Forster, J., Lake, I. R., Watkinson, A. R., \& Gill, J. A. (2014). Marine dependent livelihoods and resilience to environmental change: A case study of Anguilla. Marine Policy, 45, 204-212.

Forsyth, T. (2013). Community-based adaptation: A review of past and future challenges. WIREs Climate Change, 4(5), 439-446.

Hahn, M., \& Fröde, A. (2011). Climate proofing for development: Adapting to climate change, reducing risk. Eschborn. Retrieved from https://www.prevention web.net/files/globalplatform/entry_bg_paper giz2011 climateproofing.pdf.

Hogarth, J. R., \& Wójcik, D. (2016). An evolutionary approach to adaptive capacity assessment: A case study of Soufriere, Saint Lucia. Sustainability, 8(3), 228.

Hunt, A., \& Watkiss, P. (2011). Climate change impacts and adaptation in cities: A review of the literature. Climatic Change, 104(1), 13-49.

IPCC. (2018). Summary for policymakers. In V. Masson-Delmotte, P. Zhai, H.-O. Pörtner, D. Roberts, J. Skea, P.R. Shukla, A. Pirani, W. Moufouma-Okia, C. Péan, R. Pidcock, S. Connors, J.B.R. Matthews, Y. Chen, X. Zhou, M.I. Gomis, E. Lonnoy, T. Maycock, M. Tignor, and T. Waterfield (Eds.), Global warming of $1.5^{\circ} \mathrm{C}$. An IPCC Special Report on the impacts of global warming of $1.5^{\circ} \mathrm{C}$ above pre-industrial levels and related global greenhouse gas emission pathways, in the context of strengthening the global response to the threat of climate change, sustainable development, and efforts to eradicate poverty. In Press.

Karmalkar, A. V., Taylor, M. A., Campbell, J., Stephenson, T., New, M., Centella, A., ... Charlery, J. (2013). A review of observed and projected changes in climate for the islands in the Caribbean. Atmósfera, 26(2), 283-309.

Karnauskas, K. B., Schleussner, C.-F., Donnelly, J. P., \& Anchukaitis, K. J. (2018). Freshwater stress on small island developing states: Population projections and aridity changes at 1.5 and $2{ }^{\circ} \mathrm{C}$. Regional Environmental Change, 18(8), 2273-2282.

Kelman, I. (2010). Hearing local voices from Small Island Developing States for climate change. Local Environment, 15(7), 605-619.

Lacey, J., Howden, M., Cvitanovic, C., \& Colvin, R. M. (2018). Understanding and managing trust at the climate science-policy interface. Nature Climate Change, $8(1), 22-28$.

Lallo, C. H. O., Cohen, J., Rankine, D., Taylor, M., Cambell, J., \& Stephenson, T. (2018). Characterizing heat stress on livestock using the temperature humidity index (THI) - prospects for a warmer Caribbean. Regional Environmental Change, $18(8), 2329-2340$.

Lamhauge, N., Lanzi, E., \& Agrawala, S. (2013). The use of indicators for monitoring and evaluation of adaptation: Lessons from development cooperation agencies. Climate and Development, 5(3), 229-241.

Lewsey, C., Cid, G., \& Kruse, E. (2004). Assessing climate change impacts on coastal infrastructure in the Eastern Caribbean. Marine Policy, 28(5), 393-409. 
Mercer, J., Kelman, I., Alfthan, B., Kurvits, T., Mercer, J., Kelman, I., ... Kurvits, T. (2012). Ecosystem-based adaptation to climate change in Caribbean Small Island Developing States: Integrating local and external knowledge. Sustainability, 4(8), 1908-1932.

Middelbeek, L., Kolle, K., \& Verrest, H. (2014). Built to last? Local climate change adaptation and governance in the Caribbean - The case of an informal urban settlement in Trinidad and Tobago. Urban Climate, 8, 138-154.

Mimura, N., Pulwarty, R. S., Duc, D. M., Elshinnawy, I., Redsteer, M. H., Huang, H.-Q., ... Press, C. U. (2014). Adaptation planning and implementation. In K. J. M. Field, C.B., V.R. Barros, D.J. Dokken, A. N. L. M.D. Mastrandrea, T.E. Bilir, M. Chatterjee, K.L. Ebi, Y.O. Estrada, R.C. Genova, B. Girma, E.S. Kissel, \& and L. L. W. S. MacCracken, P.R. Mastrandrea (Eds.), Climate Change 2014: Impacts, Adaptation, and Vulnerability. Part A: Global and Sectoral Aspects. Contribution of Working Group Il to the Fifth Assessment Report of the Intergovernmental Panel on Climate Change. Cambridge, UK: Cambridge University Press.

Monioudi, I., Asariotis, R., Becker, A., Bhat, C., Dowding-Gooden, D., Esteban, M., ... Witkop, R. (2018). Climate change impacts on critical international transportation assets of Caribbean Small Island Developing States (SIDS): The case of Jamaica and Saint Lucia. Regional Environmental Change, 18(8), 22112225.

Mycoo, M. A. (2017, November 13). Beyond $1.5^{\circ} \mathrm{C}$ : Vulnerabilities and adaptation strategies for Caribbean Small Island Developing States. Regional Environmental Change, pp. 1-13.

Nurse, L. A., McLean, R. F., Agard Trinidad, J., Pascal Briguglio, L., DuvatMagnan, V., Pelesikoti, N., ... White, L. (2014). Small islands. In K. L. E. Barros, V.R., C.B. Field, D.J. Dokken, M.D. Mastrandrea, K.J. Mach, T.E. Bilir, M. Chatterjee \& and L. L. W. Y.O. Estrada, R.C. Genova, B. Girma, E.S. Kissel, A.N. Levy, S. MacCracken, P.R. Mastrandrea (Eds.), Climate Change 2014: Impacts, Adaptation, and Vulnerability. Part B: Regional Aspects. Contribution of Working Group II to the Fifth Assessment Report of the Intergovernmental Panel on Climate Change (p. 42). Cambridge, UK: Cambridge University Press.

Palanisamy, H., Becker, M., Meyssignac, B., Henry, O., \& Cazenave, A. (2012). Regional sea level change and variability in the Caribbean sea since 1950. Journal of Geodetic Science, 2(2), 125-133.

Pierre-Nathoniel, D. (2017). Working towards a Caribbean regional approach to monitoring and evaluating NAPs - NAP global network. Retrieved from http://napglobalnetwork.org/2017/01/working-towards-caribbean-regionalapproach-monitoring-evaluating-naps/.

Popke, J., Curtis, S., \& Gamble, D. W. (2016). A social justice framing of climate change discourse and policy: Adaptation, resilience and vulnerability in a Jamaican agricultural landscape. Geoforum, 73, 70-80.

Rahat, S., \& Holvoet, N. (2016). Towards a diagnostic tool for assessing the monitoring and evaluation system of climate change programs. (IOB working paper 2016.04). 
Antwerp: University of Antwerp.

Rhiney, K. (2015). Geographies of Caribbean vulnerability in a changing climate: Issues and trends. Geography Compass, 9(3), 97-114.

Rhiney, K., Eitzinger, A., Farrell, A. D., \& Prager, S. D. (2018). Assessing the implications of a $1.5^{\circ} \mathrm{C}$ temperature limit for the Jamaican agriculture sector. Regional Environmental Change, 18(8), 2313-2327.

Robinson, S. (2017). Mainstreaming climate change adaptation in small island developing states. Climate and Development, 1-13.

Robinson, S.-A. (2018). Adapting to climate change at the national level in Caribbean small island developing states. Island Studies Journal, 13(1), 79-100.

Robinson, S.-A., \& Gilfillan, D. (2017). Regional organisations and climate change adaptation in small island developing states. Regional Environmental Change, 17(4), 989-1004.

Scobie, M. (2018). Accountability in climate change governance and Caribbean SIDS. Environment, Development and Sustainability, 20(2), 769-787.

Scott, D., Simpson, M. C., \& Sim, R. (2012). The vulnerability of Caribbean coastal tourism to scenarios of climate change related sea level rise. Journal of Sustainable Tourism, 20(6), 883-898.

Smith, R.-A. J., \& Rhiney, K. (2016). Climate (in)justice, vulnerability and livelihoods in the Caribbean: The case of the indigenous Caribs in northeastern St. Vincent. Geoforum, 73, 22-31.

Thomas, A., \& Lindo, S. (2019). Disappearing islands: Small Island Developing States and climate change. In M. Chatterjee (Ed.), Environment issues: Science, policy, and diplomacy (pp. 172-181). Cognella.

Tompkins, E. L. (2005). Planning for climate change in small islands: Insights from national hurricane preparedness in the Cayman Islands. Global Environmental Change, 15(2), 139-149.

Tompkins, E. L., Lemos, M. C., \& Boyd, E. (2008). A less disastrous disaster: Managing response to climate-driven hazards in the Cayman Islands and NE Brazil. Global Environmental Change, 18(4), 736-745.

UKCIP. (2010). The UKCIP Adaptation Wizard V 3.0. UKCIP, Oxford.

UN-OHRLLS. (2017). Small Island Developing States in numbers. New York. Retrieved from http://unohrlls.org/custom-content/uploads/2017/09/SIDS-InNumbers_Updated-Climate-Change-Edition-2017.pdf.

Walker, W. E., Haasnoot, M., \& Kwakkel, J. H. (2013). Adapt or perish: A review of planning approaches for adaptation under deep uncertainty. Sustainability, 5(3), 955-979.

Wise, R. M., Fazey, I., Stafford Smith, M., Park, S. E., Eakin, H. C., Archer Van Garderen, E. R. M., \& Campbell, B. (2014). Reconceptualising adaptation to climate change as part of pathways of change and response. Global Environmental Change, 28, 325-336. 